\title{
The synergistic reno-protective effect of Rhizophora mucronata and Avicennia marina aqueous extracts against diabetes induced renal changes
}

\section{Obidallah Hamdan Ali Al-Jaghthmi ${ }^{1 *}$, Isam El Din Mohamed El Amin Abu Zeid ${ }^{1,2}$, Hassan Mohammad Heba ${ }^{1}$}

\begin{abstract}
${ }^{1}$ Department of Biological Sciences, Faculty of Sciences, King Abdulaziz University, Jeddah, Saudi Arabia ${ }^{2}$ Princess Dr. Najla Bint Saud Al-Saud Center for Excellence Research in Biotechnology, King Abdulaziz University, Jeddah, Saudi Arabia
\end{abstract}

Received: 27 June 2020

Accepted: 31 July 2020

\section{* Correspondence:}

Dr. Obidallah Hamdan Ali Al-Jaghthmi,

Email: aljagthmi.o.h.2030@gmail.com

Copyright: ( $)$ the author(s), publisher and licensee Medip Academy. This is an open-access article distributed under the terms of the Creative Commons Attribution Non-Commercial License, which permits unrestricted non-commercial use, distribution, and reproduction in any medium, provided the original work is properly cited.

\begin{abstract}
Background: The conventional medications of diabetes mellitus have many side effects that bring to diabetic cases, so there is a need for introducing natural remedies with antidiabetic effect. The objectives of this study aimed to evaluate the hypoglycemic and antidiabetic effects of aqueous extracts of a mixture of $R$. mucronata and A. marina against experimentally streptozotocin (STZ) induced diabetic rats and to assess its efficacy in alleviating diabetesinduced impact on kidney function.

Methods: Sixty rats distributed into four groups $(\mathrm{n}=15)$ were used in this study. They included the control, STZinduced diabetic, STZ-induced diabetic treated with a mixture of Rhizophora mucronata and Avicennia marina extract and non-diabetic group received a mixture of Rhizophora mucronata and Avicennia marina extract. After 6 weeks of treatment, the biochemical and histological alterations were investigated in all rats.

Results: Daily oral administration of a mixture of $R$. mucronata and A. marina leaves extract to STZ-induced diabetic significant $(\mathrm{p} \leq 0.001)$ increase serum insulin levels and reduced fasting blood glucose levels, serum BUN and uric acid compared to the untreated diabetic rats. This mixture also improved the renal degeneration and inflammation induced by diabetes and reduced the number of the apoptotic cell in both renal cortex and medulla.

Conclusions: The mixture of $R$. mucronata and $A$. marina extract significantly improve the diabetes-associated biochemical and histopathological renal changes indicating its potential effect as a natural nephroprotective agent against diabetic-induced nephropathy.
\end{abstract}

Keywords: Diabetes, Streptozotocin, $R$. mucronata, A. marina, Apoptosis, Creatinine

\section{INTRODUCTION}

Type 1 diabetes mellitus (T1 DM) is insulin dependent and results when T-cells destroy the insulin-secreting $\beta$ cells, while T2 DM occurs when there is a rise in glucose levels with mounting cell's resistant to inadequate insulin. ${ }^{1}$ Considerable scientific research suggested that under oxidative stress situations, reactive oxygen species (ROS) are produced. However, it is believed that the equilibrium between the oxidation and antioxidation processes results in causing human diseases including diabetes. $^{2}$

Due to the side effects that conventional medications bring to diabetic cases, research has turned to the traditional remedies in the form of plants. ${ }^{3}$ There are already 1,200 plants that received acknowledgement being a possible anti-diabetic remedy. ${ }^{4}$ Medicinal plants 
contain high levels of saponins, flavonoids, carotenoids, glycosides, antioxidants, terpenoids, and alkaloids needed in the human body. Aside from the anti-diabetic effects of medicinal plants, they also help the body to perform essential metabolic functioning. ${ }^{5}$ Since medicinal plants are natural sources, they have fewer side effects, and they offer evidence for the synthesis of novel and improved medicines for the treatment of diabetes. ${ }^{6}$ One of these plants with strong antidiabetic property is the mangrove plant.

Mangroves are salt resistant plants cultivated in internal areas of tropical, sub-tropical and shorelines. ${ }^{7}$ There are black, white, and red mangroves that can either be true or special species. Special species of mangroves are well developed to acclimatize to anaerobic, waterlogged and alkaline conditions. A. marina is species of the genus Avicenniaceae from the Acanthaceae family. It is characterized by its grey stem hue, which sometimes is white depending on its geographical location. ${ }^{8}$ From its wider family of Rhizophoraceae, R. mucronata is one of the many species of the genus Rhizophora that has other spatial relations including $R$. apiculata and Rhizophora stylosa that thrive in the western Pacific and the Indian subcontinent. ${ }^{9}$

Previous studies proved that $R$. mucronata extracts have antidiabetic effects through acting on $\beta$-cells that stimulate insulin secretion. ${ }^{10,11}$ Adding to that Moghaddam et al and Kamaei et al reported that $A$. marina extract has a significant antidiabetic effect on STZ-induced diabetic rats. ${ }^{12,13}$ To our knowledge, no studies have investigated the antidiabetic effect of the combination of $R$. mucronata and $A$. marina extract in an animal model of diabetes. Therefore, the aim of this study was to evaluate the hypoglycemic and antidiabetic effects of aqueous extracts of a mixture of $R$. mucronata and A. marina against experimentally STZ-induced diabetic rats and to assess its efficacy in alleviating diabetes-induced impact on kidney function and structure.

\section{METHODS}

\section{Plants extraction}

Rhizophora mucronata was collected from Farasan Island, Jizan. The island is located approximately $50 \mathrm{~km}$ offshore from Jizan city in the Red Sea, south western part of Kingdom Saudi Arabia (KSA). On the other hand, A. marina was collected from Shuaiba area, KSA. Shuaiba is located in Red Sea coast, approximately 100 $\mathrm{km}$ South of Jeddah (Figure 1). Aqueous extracts of plant leaves were prepared as was previous described. ${ }^{14}$

\section{Experimental design}

This experiment was performed on 60 adult male Wistar albino rats (200 to $250 \mathrm{~g}$ average body weight). The animals were housed in individual cages in the animal house at constant temperature $\left(24 \pm 1^{\circ} \mathrm{C}\right)$ and humidity
$(55 \pm 10 \%)$. The rats fed the standard commercial chow and water ad libitum. They were maintained in accordance with the international ethical guidelines for the care of laboratory animals and all experimental procedures were approved by "the animal care and use committee of the King Abdulaziz University".

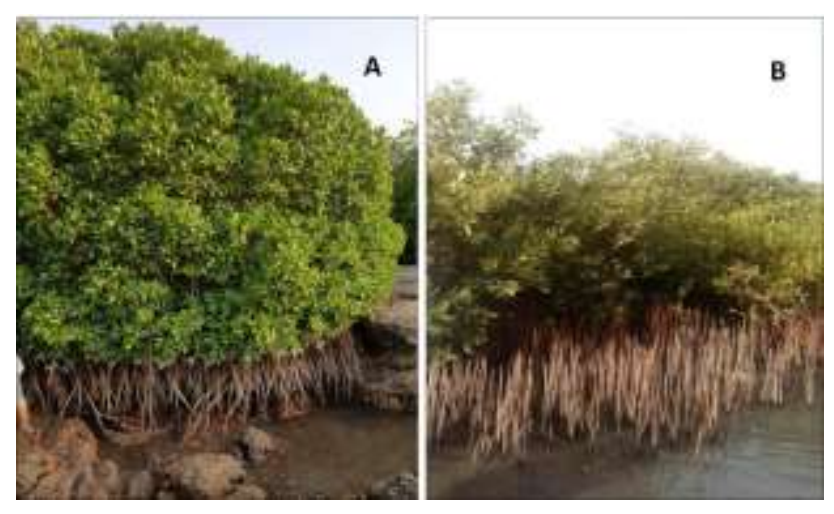

Figure 1: (A) Rhizophora mucronata and (B) Avicennia marina.

The overnight-fasted rats were intraperitoneally injected with a single dose $(60 \mathrm{mg} / \mathrm{kg})$ of freshly prepared streptozotocin (STZ) in order to induce diabetes (AlHariri, 2012). Three days after STZ injection, the fasting blood glucose (FBG) levels were measured in blood samples taken from rats' tail by using a one touch ultraglucometer (Lifescan, Johnson and Johnson, Milpitas, CA, USA). Animals with blood glucose levels $\geq 250$ $\mathrm{mg} / \mathrm{dl}$ were considered diabetic and used for the experiment. ${ }^{11}$ This day was considered the first day of the experiment

The experiment included four equal groups $(n=15$ rats each). Group 1 included control rats that received water and fed ad libitum. Group 2 included STZ-induced untreated diabetic rats. Groups 3 included diabetic rats treated orally with a mixture of aqueous leaf extracts of R. mucronata (200 mg/kg BW/day) and A. marina (200 $\mathrm{mg} / \mathrm{kg} \mathrm{BW} /$ day). Group 4 included non-diabetic rats that received an aqueous leaf extract of a mixture of $R$. mucronata and $A$. marina leaf extracts. The treatments started on the $4^{\text {th }}$ day after STZ injection and continued daily for six weeks.

\section{Biochemical assessment}

To measure the glucose levels, fasting blood samples were collected from the tail vein of the rats, and glucose levels were then determined using a one touch ultraglucometer (Lifescan, Johnson and Johnson, Milpitas, CA, USA).

In order to obtain serum, blood was collected from retroorbital venous plexus of rats at the $6^{\text {th }}$ week, left for clotting at room temperature and serum was separated by centrifugation at $3000 \mathrm{rpm}$ for 20 minutes. Serum insulin levels were measured in the serum using insulin ELISA 
kits which includes an enzyme immunoassay for the quantitative determination of insulin in sera of rats (Cat. no. ezrmi-13kelisa, Billerica, MA, USA) according to a method. ${ }^{11}$

The serum creatinine and BUN levels were determined in the serum according to Henry et al. ${ }^{16}$ The method of young was used to determine the level of uric acid in the serum. ${ }^{17}$

\section{Histopathological examinations}

The kidneys were dissected after scarification of rats at the $6^{\text {th }}$ week post-treatments and were fixed in $10 \%$ neutral formalin, processed and embedded in paraffin. Sections with $5 \mu \mathrm{m}$ thickness were cut, stained with hematoxylin and eosin ( $\mathrm{H}$ and $\mathrm{E})$, and then examined for histopathological assessment using light microscopy. ${ }^{18}$

The standard immunohistochemical methods were used for detection of apoptotic using anticaspase-3 antibodies. The biotin-streptavidin (BSA) system was used to visualize the reaction. Diaminobenzidine (DAB) was used as chromogen since it allows a permanent preparation. Hematoxylin counterstain was done.

\section{Statistical analysis}

The obtained data in this study were analysed using statistical package for social sciences (SPSS) version 24. Results were expressed as mean \pm standard error (SE). Statistical significance of the difference between groups, with more than two categories, was determined by oneway analysis of variance (ANOVA) followed by least significant difference (LSD) post-hoc test. The values were considered significantly different when the $\mathrm{P}$ value was $\leq 0.05 .^{19}$

\section{RESULTS}

At the end of the experimental period, the FBG levels of STZ-induced diabetic rats (G2) remained significantly elevated $(p \leq 0.001)$ compared to control group $(G 1)$. The daily oral administration of STZ-induced diabetic rats (G3) with a mixture of $R$. mucronata and $A$. marina leaves extract induced a significant decree $(\mathrm{p} \leq 0.05)$ in blood glucose levels as compared to the diabetic group (G2) (Figure 2A).

Regarding the serum insulin level, it showed a highly significant decrease $(\mathrm{p} \leq 0.001)$ in $\mathrm{STZ}$-induced diabetic control rats (G2) compared to control rats (G1). On the other hand, daily oral administration of a mixture of $R$. mucronata and A. marina leaves extract to STZ-induced diabetic rats (G3) revealed a significant increase $(\mathrm{p} \leq 0.001)$ in serum insulin levels compared to the diabetic group (G2) (Figure 2B).

Serum ccreatinine ( $\mu \mathrm{mol} / \mathrm{l})$ of STZ-induced diabetic rats (G2) exhibited a significant elevation $(\mathrm{p} \leq 0.01)$ compared to control group (G1), while it significantly decrease $(\mathrm{p} \leq 0.05)$ in diabetic rats treated with a mixture of $R$. mucronata and A. marina extract (G3) compared to STZinduced diabetic rats $(\mathrm{G} 2)$ (Figure $2 \mathrm{C}$ ).

STZ injection induced a significant increase $(\mathrm{p} \leq 0.001)$ in the serum BUN levels $(\mathrm{mmol} / \mathrm{L})$ of diabetic control rats (G2) in comparison to control group (G1). The daily oral administration of extracts of a mixture of $R$. mucronata and A. marina to STZ-induced diabetic rats (G3) resulted in a significant decrease $(\mathrm{p} \leq 0.05)$ in the levels of serum BUN compared to STZ-induced diabetic rats (G2) (Figure 2D).

The serum uric acid levels in diabetic rats (G2) were significantly increased $(\mathrm{p} \leq 0.05)$ compared to control group (G1). Daily oral administration of mixture of $A$. marina and $R$. mucronata to diabetic rats (G3) induced a non-significant reduction in the level of uric acid compared to diabetic group (G1) (Figure 2E).

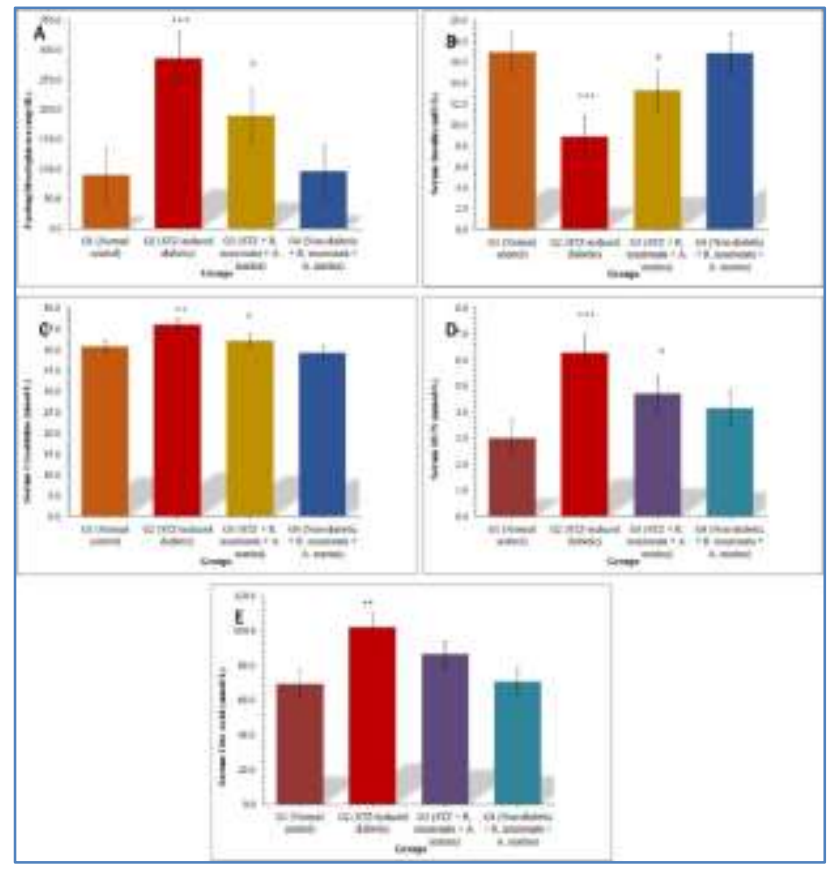

Figure 2: Effect of extract of a mixture of $\boldsymbol{R}$. mucronata and $A$. marina on levels of (A) blood glucose (mg/dl) levels, (B) serum insulin (ml U/l), (C) serum creatinine $(\mu \mathrm{mol} / \mathrm{l}),(D)$ serum BUN (mmol/l) and (E) serum uric acid ( $\mu \mathrm{mol} / \mathrm{L})$ in the studied groups at six weeks after STZ injection.

Results are expressed as mean \pm SEM $(n=15)$. Mean value is significantly different at $\mathrm{p} \leq 0.01 * *$ compared to normal control group. Mean value is significantly different at $\mathrm{p} \leq 0.05^{\#}$ compared to STZ-induced diabetic group.

\section{Histopathological results}

When kidney sections of control rats (G1) were examined it was noticed that the renal parenchyma and stroma were intact with normal appearance of the nephron (Figure 3). 


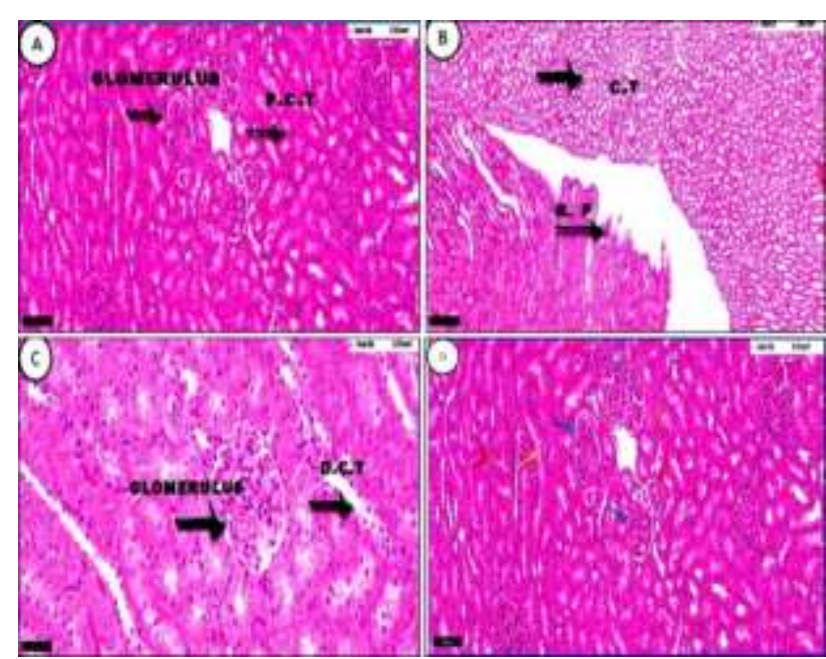

Figure 3: Photo-micrograph for rat's kidney G1, (normal rats), showing normal features of the nephron units including glomerulus, proximal convoluted tubules, distal convoluted tubules, beside collecting tubules, papillary and pelvic structures (arrows) $\mathrm{H}$ and E. Scale bars, $50 \mathrm{um}$ (C), 100 um (A), $200 \mathrm{um}$ (B). (D) Corresponding illustrative photomicrograph to show the normal histo-morphology of nephron units with preserved glomeruli (blue arrows), proximal and distal convoluted tubules (golden yellow and yellow arrows) and renal inter tubular blood vessels and capillaries (red arrows) ( $\mathrm{Hx}$ and $\mathrm{E}$ scale bar 100 um).

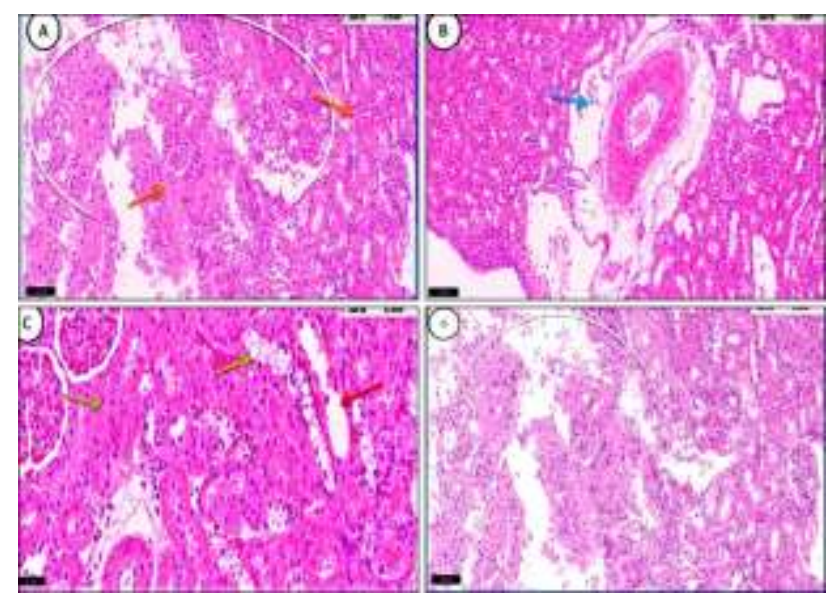

Figure 4: Photo-micrograph of rat's kidney G2 (STZinduced diabetic rats, $60 \mathrm{mg}$ STZ/kg BW, Single IP dose) showing focal coagulative necrosis (A, white circle and golden yellow arrows), perivascular edema

(B, blue arrow), cloudy swelling and hydropic degenerations in the tubular epithelium $(C$, green arrows) beside mild dilatation in some tubules $(\mathrm{C}$, red arrow). H and E. Scale bars, 50 um (C), 100 ums (A, B). (D) Corresponding illustrative photo-micrograph to show the coagulative necrosis (white circle and white arrows) (Hx and E scale bar $100 \mathrm{um}$ ).

However, renal sections of diabetic rats $(\mathrm{G} 2)$ revealed moderate multifocal areas of coagulative necrosis and distinct inflammatory reaction. Additionally, variable degrees of cloudy swelling, vacuolar and hydropic degeneration were noticed. Mild dilatation of some distal convoluted tubules and collecting tubules with partial atrophy of their lining epithelium as well as perivascular edema and mild to moderate congestion of inter tubular and glomerular blood vessels and capillaries were observed (Figure 4).

Most of the examined kidney sections of STZ-induced diabetic rats treated with a mixture of $R$. mucronata and A. marina (G3) showed apparently healthy nephron (glomeruli and tubules). Other sections revealed moderate congestion of renal and pelvic blood vessels sometimes with mild edematous changes besides, characteristic intra-tubular hyaline casts were also seen (Figure 5). Serial sections from kidneys of non-diabetic rats received a mixture of $R$. mucronata and A. marina (G4) revealed apparently normal nephron units with preserved tubular structures, glomeruli. A few sections denoted mild congestion of renal blood vessels (Figure 6).

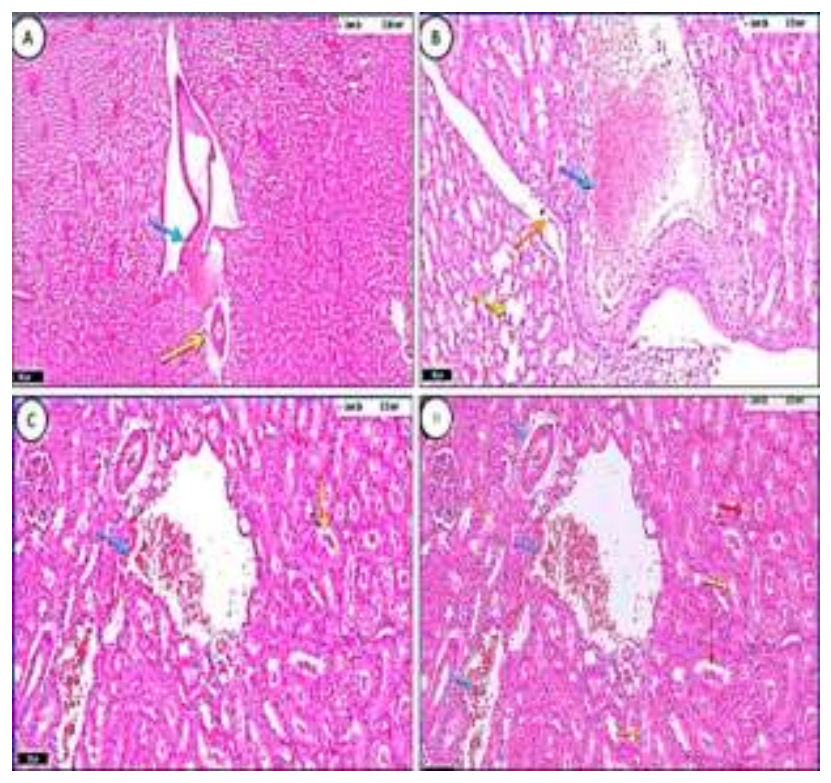

Figure 5: Photo-micrograph of rat's kidney G3, (STZ-induced diabetic rat, treated with a mixture of R. mucronata $200 \mathrm{mg}$ and A. marina $200 \mathrm{mg} / \mathrm{kg} \mathrm{BW}$, daily oral dose for 6 weeks), showing congestion of renal and pelvic blood vessels ( $\mathrm{A}, \mathrm{B}, \mathrm{C}$, blue arrows), perivascular edema (A, yellow arrow), degenerative and exfoliative changes in some tubular and pelvic epithelia ( $B$, green and golden yellow arrows), beside intratubular hyaline casts $(\mathrm{C}$, green arrow). $\mathrm{H}$ and $\mathrm{E}$ scale bars, 100 ums (B, C), 500 um (A). (D)

Corresponding illustrative photo-micrograph to show congestion of renal blood vessels and perivascular edema (blue arrows), degenerative changes (golden yellow arrow), apoptotic changes (black arrow) and intratubular hyaline casts (red arrows) beside some normal nephron units (glomeruli and tubules) (yellow arrows) (Hx and E scale bar, $100 \mathrm{um}$ ). 


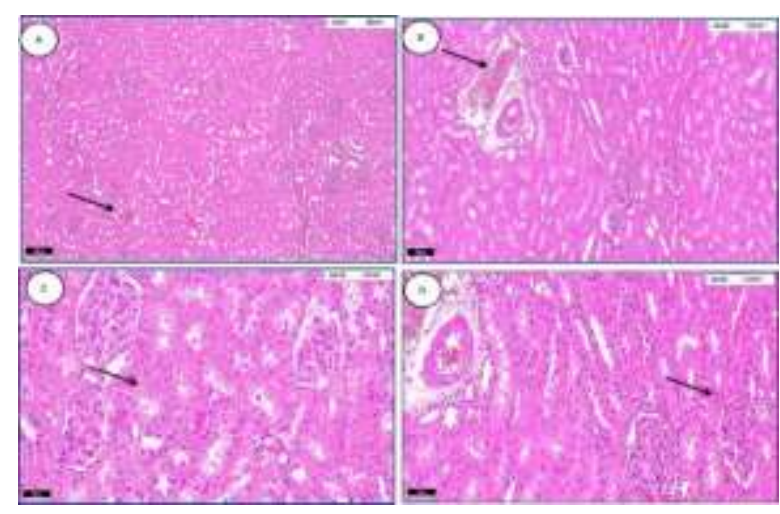

Figure 6: Photo-micrograph of rat's kidney, G4, nondiabetic rats treated with a mixture of $R$. mucronata $200 \mathrm{mg}$ and $A$. marina $200 \mathrm{mg} / \mathrm{kg} \mathrm{BW}$ (daily oral dose for 6 weeks), showing apparently normal nephron units with preserved tubular structures apart from some area of mild congestion of renal blood vessels (arrow) (Hx and E scale bars 200 um (A), 100 um (B, D), 50 um (C).

\section{Immunohistochemical results}

Kidney sections of normal rats (G1) showed no apoptotic changes apart from few cells in the medullary collecting tubules $(0.5-1 \%) / \mathrm{HPF}$ Figure 7 (A and $\mathrm{B})$.

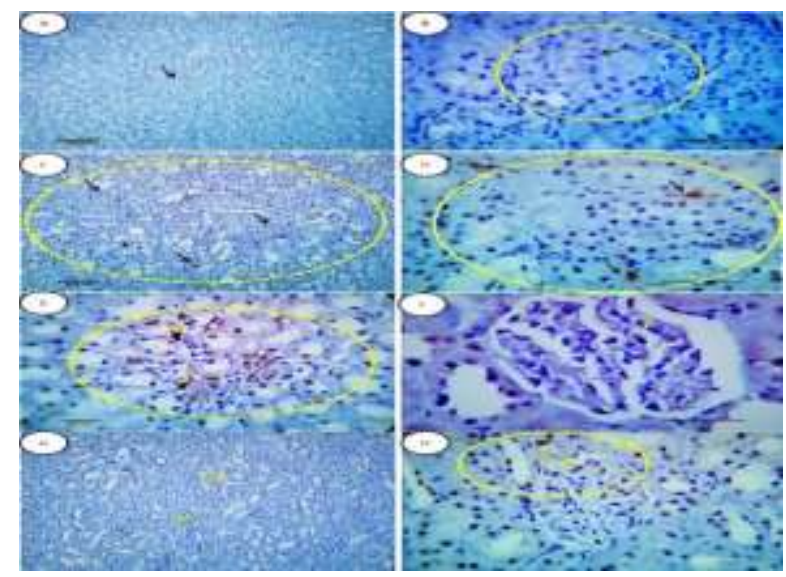

Figure 7: (A and B) Photo-micrographs of immunestained rat's kidney of G1 (normal rats) showing normal renal parenchyma free from any apoptotic changes (black arrows). C, D: G2, (STZ-induced diabetic rats), showing about 3-5\%/HPF of the tubular epithelium, particularly in the medulla positive for caspase-3. (E and F) G3, (STZ-induced diabetic rat, treated with a mixture of $R$. mucronata and $A$. marina showing a few sections with 3-5\% of cells/HPF of the tubular epithelium and 5-7 cells of

the stromal cells (yellow arrows), positively stained for caspase-3. ( $\mathrm{G}$ and $\mathrm{H}$ ) G4, non-diabetic rats treated with a mixture of $R$. mucronata and A. marina showing in a few sections $1-2 \%$ of cells/HPF with positive reaction (yellow arrows).

Anti-caspase-3 immunohistochemistry, scale bars (A, C, E, G: 100, B, D, F, H: 50) um.
Meanwhile, renal tissue of STZ-induced diabetic rats (G2) revealed about $3-5 \%$ positive apoptotic reaction of the tubular epithelium, particularly in the medulla Figure 7 (C and D). However, renal sections of STZ-induced diabetic treated with a mixture of $R$. mucronata and $A$. marina (G3) were free of apoptosis in most sections apart from few sections that showed 3-5\% of cells/HPF of the tubular epithelium and $5-7 \%$ of the stromal cells Figure 7 (E and F). Most of the renal tubular, glomerular and stromal structures of non-diabetic rats treated with a mixture of $R$. mucronata and A. marina (G4) denoted negative reaction to the apoptotic caspase-3. A few sections revealed $1-2 \%$ cells/HPF with positive reactivity Figure 7 ( $\mathrm{G}$ and $\mathrm{H})$.

\section{DISCUSSION}

All patients with type 1 diabetes need insulin hormone treatment for good health (insulin-dependent), unless they receive islets cells or whole organ transplant. Several patients with type 2 diabetes could need this hormone, once their $\beta$-cell function declines over time. Insulin hormone resistance is additionally associated with obesity, which is a vital predisposing issue liable for the occurrence of type 2 diabetes, whether naturally or experimentally. ${ }^{20}$

Although the antidiabetic effects of $R$. mucronata extracts and $A$. marina extract have been previously reported, the antidiabetic effect of the combination of $R$. mucronata and A. marina extract is not investigated till now. ${ }^{10-13}$ Therefore, this study was to design to investigate the efficacy of such combination of extracts in STZ-induced diabetic model.

In the present study diabetes was induced by administering a single dose of STZ by IP injection of $60 \mathrm{mg} / \mathrm{kg} \mathrm{BW}$ that was confirmed by measuring blood glucose level on the $3^{\text {rd }}$ day after STZ injection. There was a dramatic elevation of the blood glucose levels after induction of diabetes compared with the normal control rats. This was in concordance with treatment of STZ-induced diabetic rats with a mixture of $R$. mucronata and A. marina induced a significant decrease in levels of blood glucose as well as a significant increase in insulin level in comparison to the diabetic control group. ${ }^{11}$ The results of the current investigation are in accordance with that of Adhikari et al who reported that, regular administration of extract of $R$. mucronata leaves maintained the normal serum insulin level. ${ }^{21}$ The authors added that $R$. mucronata leaves are a rich source of magnesium content and the gas chromatographic study showed the presence of squalene. In the current study the promising antidiabetic effect of $R$. mucronata extracts may be associated with the insulin mimicking property of its phytochemicals. Such finding coincide the data reported by Ray et al. ${ }^{22}$ Moreover, the active phytoconstituents of the $R$. mucronata leaves mostly are the triterpene, phenolic acid, and its derivatives. These bioactive compounds can be promising source of therapeutic approach for the multifaceted disease like diabetes and its associated complications. ${ }^{21}$ 
Nebula et al said that $R$. mucronata could restrain carbohydrate digestion and absorption. ${ }^{23}$ They added that the leaf extracts of $R$. mucronata have potential antidiabetic capacity due to the presence of an insulin-like protein. On the other hand, Eldeen and Effendy, mentioned that the anti-hyperglycemic activity of $R$. mucronata is associated with its $\alpha$-glycosidase inhibition potential. ${ }^{24}$ Gupta et al recently declared that the absolute or relative deficiencies in insulin secretion by pancreatic $\beta$-cells and/or insulin action could be modulated by plant cells secondary metabolites, which are biologically active constituents with therapeutic and prophylactic applications in humans. ${ }^{25}$ These metabolites include alkaloides, glycosides, flavonoids, terpenoids, tannins, resins, lignins and saponins. Parallel to the abovementioned observations, Moghaddam et al and Kamaei et al concluded that hydrous and hydroalcoholic extract of $A$. marina meaningfully decreased serum glucose measures and increased serum insulin level in STZ-induced diabetic rats. ${ }^{12,13}$ All the above-mentioned mechanism could explain for the efficient antidiabetic effect of the mixture of $R$. mucronata and A. marina evidenced in this study.

It was reported that "the earliest detectable abnormality of nephropathy is microalbuminuria followed by decrease in glomerular filtration rate (GFR) and increase in serum creatinine concentrations". ${ }^{26}$ Among the main findings revealed by the current study was the renoprotective effect induced by the mixture of $R$. mucronata and $A$. marina and evidenced by the significant decrease in serum creatinine level of STZ-induced diabetic rats treated with the extract mixture compared to the untreated diabetic rats. This might be attributed to A. marina in the extract. Gandomani and Malati indicated that A. marina at a dose of $400 \mathrm{mg} / \mathrm{kg}$ induced a significant renoprotective effect by decreasing the serum pro-inflammatory cytokines in diabetic rats. ${ }^{27}$ Suarez et al reported that good glycemic control could decrease the incidence of diabetic nephropathy. ${ }^{26}$

Serum urea significantly elevated with increased duration of diabetes which is a risk factor for the kidney damage progression. "Over a time high blood sugar level damage millions of nephron an increase in serum urea occurs when there is damage to the kidney". ${ }^{28}$ The mechanisms underlying the disturbances of glucose homeostasis are becoming clearer and likely involve retention of uremic metabolites including urea. ${ }^{29}$ In the current study administration of the mixture of $R$. mucronata and $A$. marina significantly decrease serum urea level in STZinduced diabetic rats compared to the untreated diabetic rats.

In the current study there was significant increase in serum uric acid of STZ-induced diabetic rats as compared with normal rats. Non-significant changes were observed in the levels of uric acid of all diabetic rats treated with the mixture of the extracts of $R$. mucronata and A. marina when compared with STZ-induced diabetic rats. On contrary to this study, the ethanol extract of A. marina exudate induced anti-hyperuricemic activity through invitro inhibition of xanthine oxidase (XOD). ${ }^{30}$

In this study, the renal tissue the diabetic showed focal areas of coagulative necrosis, inflammation, cloudy swelling, and partial atrophy of the tubular lining epithelium, perivascular edema and congestion of inter tubular and glomerular capillaries as well as increased apoptosis. These findings were in agreement with. ${ }^{31}$

It was reported that the ethanolic extract of Rhizophora mucronata leaves administrated to STZ-induced diabetic rats $(250$ and $500 \mathrm{mg} / \mathrm{kg}$ ) resulted in nearly intact renal tissue with normal glomerulus, normal basement membrane, and capillaries without any inflammatory cells. ${ }^{31}$ Unfortunately, there were no previous researches conducted to study the effect of A. marina alone or in combination with $R$. mucronata on the renal structure in diabetic animal models. In a study conducted by Mirazi et al, the reno-protective effect of Avicennia marina against carbon tetrachloride induced renal pathology has been investigated. $^{32}$ They found that the hydroalcoholic extract of mangrove (Avicennia marina L.) at doses of 200,400 and $800 \mathrm{ml} / \mathrm{kg}$ and especially at 400 and 800 $\mathrm{ml} / \mathrm{kg}$ doses could improve the necrosis and inflammation induced by carbon tetrachloride in male rats.

This improvement or recovery was likely due to the presence of antioxidant compounds such as flavonoids in mangrove leaves extract. ${ }^{32}$

In this study, kidney sections of diabetic rats treated with a mixture of $R$. mucronata and A. marina showed apparently healthy nephron (glomeruli and tubules). This could be attributed to the synergetic renoprotective effect of $R$. mucronata and A. marina that was previously described.

\section{CONCLUSION}

In conclusion, diabetes mellitus has a negative impact on the structure of the kidney. It induced a significant increase in the serum levels creatinine, BUN and uric acid. The use of a mixture of $R$. mucronata and A. marina extract significantly decreased these parameters. The mixture extract also improved the diabetes-associated histopathological renal changes. Due to these findings it can be concluded that a mixture of $R$. mucronata and $A$. marina extract has a potential effect as a natural nephroprotective agent against diabetic-induced nephropathy.

\section{ACKNOWLEDGEMENTS}

This work was supported by the King Abdulaziz City for Science and Technology in the Kingdom of Saudi Arabia, Grant No. (1-17-01-009-0091). The authors also, acknowledge assistance from the science and technology unit, Deanship of Scientific Research and Deanship of Graduate Studies, and also acknowledge support from the 
Department of Biological Sciences, Faculty of Science, King Abdulaziz University (KAU), Jeddah, KSA.

Funding: No funding sources

Conflict of interest: None declared

Ethical approval: The study was approved by the Institutional Ethics Committee

\section{REFERENCES}

1. Copenhaver M, Hoffman RP. Type 1 diabetes: where are we in 2017? Transl. Pediatr. 2017;6(4):359-64.

2. Sur TK, Hazra AK, Bhattacharyya D, Hazra A. Antiradical and antidiabetic properties of standardized extract of Sunderban mangrove Rhizophora mucronata. Pharmacogn Mag. 2015;11(42):389 -94.

3. Kooti W, Farokhipour M, Asadzadeh Z, Larky AD, Samani AM. The role of medicinal plants in the treatment of diabetes: a systematic review. Electron Physician. 2016;8(1):1832-42.

4. Chang CLT, Lin Y, Bartolome AP, Chen YC, Chiu SC, Yang W. Herbal therapies for type 2 diabetes mellitus: chemistry, biology, and potential application of selected plants and compounds. Evid Based Complement Alternat Med. 2013:1-33.

5. Afrisham R, Aberomand M, Ghaffari MA, Siahpoosh A, Jamalan M. Inhibitory effect of heracleum persicum and ziziphus jujuba on activity of alphaamylase. J Bot. 2015;20(2015):1-8.

6. Giovannini P, Howes MJ, Edwards SE. Medicinal plants used in the management of diabetes and its sequelae in Central America: a review. J Ethnopharmacol. 2016;184:58-71.

7. Simlai A, Roy A. Biological activities and chemical constituents of some mangrove species from Sundarban estuary: an overview. Pharmacogn Rev. 2013;7(14):170-8.

8. Thamizharasan S, Saravanan NA. Anti-bacterial potential of mangrove plant Avicennia marina against a clinical pathogen. Int J Zool Stud. 2016;1(7):14-6.

9. Ragavan P, Mohan PM, Jayaraj RSC, Ravichandran K, Saravanan S. Rhizophora mucronata var. Alokii a new variety of mangrove species from the Andaman and Nicobar Islands, India (Rhizophoraceae). Phyto Keys. 2015;52:95-103.

10. Babu MB. Bioactivity of A. marina and R. mucronata for the management of diabetes mellitus. World $\mathbf{J}$ Pharm Res. 2014;3(1):311-8.

11. Gurudeeban S, Kaliamurthi S, Thirugnanasambandam R. Positive regulation of Rhizophora mucronata poir extracts on blood glucose and lipid profile in diabetic rats. Herb Med. 2016;2:110.

12. Moghaddam FH, Mokhtari M, Kamaei L, Ahangarpour A. Effects of Avicennia Marina Leaves Aqueous and Hydro Alcoholic Extract on Streptozotocin-Induced Diabetic Male Rats. J Rafsanjan Univ Med Sci. 2012;10(4):245-54.
13. Kamaei L, Moghaddam HF, Mokhtari M, Mard SA, Moghadamnia D. Effects of Avicennia marina fruits aqueous and hydro alcoholic extract on streptozotosin induced diabetic male rats. Med Sci IAUTMU. 2017;27(1):9-16.

14. Mohamadi J, Havasian MR. The study of inhibitory effect of aqueous extract leaf of Avicennia marina (Hara) on Candida albicans, in vitro. Int J Pharm Life Sci. 2017;8:5547-51.

15. Hariri AMT. Comparison the rate of diabetes mellitus induction using streptozotocin dissolved in different solvents in male rats. J Comp Clin Path Res. 2012;1:96 -9.

16. Henry RJ, Cannon DC, Winkelman JW. "Clinical chemistry: principles and techniques," 11th Ed, Happer and Row Publishers, New York; 1974:1629.

17. Young DS. Effects of preanalytical variables on clinical laboratory tests, 2nd Ed. Washington. DC: AACC Press; 1997.

18. Fernandez TG, Suarez CL, Acosta PT, Clapes S. Influence of diabetes and gestation in blood biochemistry variables in Wistar rats. Int J Anim Sci. 2018;2:1-4.

19. Zar JH. Biostatistical analysis prentice-hall, eryelwood cliffs. N J. 1996:663.

20. Han JM, Wu D, Denroche HC, Yao Y, Verchere CB, Levings MK. IL-33 reverses an obesity-induced deficit in visceral adipose tissue ST2 + T regulatory cells and ameliorates adipose tissue inflammation and insulin resistance. J Immunol. 2019;194(10):4777-83.

21. Adhikari A, Ray M, Sur TK, Biswas S, Roy RK, Hazra AK, et al. Anti-diabetic activity of $R$. mucronata leaves in STZ-nicotinamide induced animal model. J Middle East North Afr Sci. 2018;4(8):1-7.

22. Ray M, Adhikari A, Sur TK, Biswas S, Roy RK, Das AK. Promising blood sugar lowering action of sunderban mangrove. Indian $\mathrm{J}$ Pharmacol. 2014;46(1):62-113.

23. Nebula M, Harisankar HS, Chandramohanakumar N. Metabolites and bioactivities of Rhizophoraceae mangroves. Nat Prod Bioprospect. 2013;3(5):207-32.

24. Eldeen IM, Effendy MA. Antimicrobial agents from mangrove plants and their endophytes. In MendesVilas 9th ed. Microbial pathogens and strategies for combating them: science, technology and education. Formatex microbiology book series. Formatex Res. Centre: Badajoz, Spain; 2013:872-882.

25. Gupta SC, Kunnumakkara AB, Aggarwal S, Aggarwal BB. Inflammation, a Double-Edge Sword for Cancer and Other Age-Related Diseases. Front Immunol. 2018;9:2160.

26. Suarez MLG, Thomas DB, Barisoni L, Fornoni A. Diabetic nephropathy: Is it time yet for routine kidney biopsy? World J Diabetes. 2013;4(6):245-55.

27. Gandomani MZ, Malati EF. Evaluation of protective efficacy of Avicennia marina (Forssk.) vierh leaves against complete freund's adjuvant-induced arthritis in wistar. Iran J Pharm Res. 2014;13(3):945-51. 
28. Mishra KP, Mawar A, Kare PK, Verma N. Relationship between fasting blood glucose, serum urea, serum creatinine and duration of diabetes in type-2 diabetic patients. Flora Fauna. 2015;21(1):127-32.

29. Xie Y, Bowe B, Li T, Xian H, Yan Y, Aly AZ. Higher blood urea nitrogen is associated with increased risk of incident diabetes mellitus. J Clin Invest. 2018;93(3):741-52.

30. Anam K, Susilo D, Kusrini D, Agustina LNA. Chemical constituents and inhibition xanthine oxidase activity of Avicennia marina exudate. Res J Med Plants. 2017;11(1):19-24.

31. Shrivastava B, Chinnaboina GK, Babu AMSS, Sharma GN, Singh M. Protective Role of Rhizophora Mucronata Leaves Against Streptozotocin-Induced
Diabetic Nephropathy. Int J Pharmaceutical Sci Res. 2019;10(7):3445-54.

32. Mirazi N, Movassagh SN, Kopaei RM. The protective effect of hydro-alcoholic extract of mangrove (Avicennia marina L.) leaves on kidney injury induced by carbon tetrachloride in male rats. $\mathbf{J}$ Nephropathol. 2016;5(4):118-22.

Cite this article as: Al-Jaghthmi OHA, Zeid IEDMEAA, Heba HM. The synergistic renoprotective effect of Rhizophora mucronata and Avicennia marina aqueous extracts against diabetes induced renal changes. Int J Basic Clin Pharmacol 2020;9:1317-24. 